\title{
Pelatihan Penyusunan Laporan keuangan Bagi UKM Batik Kampung Tematik di Kelurahan Mangunharjo Kecamatan Tembalang
}

\section{Training on Compilation of Financial Reports for Thematic Village Batik SMEs in Mangunharjo Village, Tembalang District}

\author{
Tri Rinawati* ${ }^{1}$, Asih Niati ${ }^{2}$, Teguh Ariefiantoro ${ }^{3}$ \\ Universitas Semarang, Kota Semarang, Indonesia \\ *Penulis Korespondensi \\ 1rinaoshin@gmail.com, ${ }^{2}$ asihniati@gmail.com, ${ }^{3}$ vwgoeh74@gmail.com
}

Riwayat Artikel: Dikirim 6 Februari 2021; Diterima 19 Mei 2021; Diterbitkan 31 Mei 2021

\begin{abstract}
Abstrak
Salah satu kampung Tematik di wilayah kecamatan Tembalang adalah Kelurahan Mangunharjo dengan nama Kampung Tematik Durenan Indah yang di bangun berdasarkan adanya kegiatan yang ada di wilayah RW 06 yaitu UKM "Batik Blekok" dan kegiatan kelompok Batik "Blibis Mas" hasil dari binaan UKM "Batik Blekok" di RW 06. Maksud dibentuknya Kampung Tematik Durenan Indah di RW 06 Kelurahan Manguharjo Kecamatan Tembalang Kota Semarang adalah meningkatkan pengetahuan atau pendidikan tentang budaya Nusantara khususnya Seni dan Budaya Lokal Kota Semarang, melestarikan budaya nasional dan lokal yang mana menjadikan ciri khas kota Semarang pada umumnya dan merupakan ciri khas unggulan produk Kelurahan Mangunharjo, pemberdayaan masyarakat bertujuan untuk menekan kemiskinan dan pengangguran, mempercantik daerah kumuh, menjunjung kearifan lokal dalam meningkatkan potensi serta pemecahan permasalahan lingkungan, menjadikan wilayah tersebut sebagai daerah pariwisata. Permasalahan yang dihadapi oleh pelaku usaha UKM Batik Blekok dan UKM Batik Blibis di antaranya di bidang manajemen keuangan, dalam hal ini adalah karena keterbatasan pengetahuan tentang pembuatan dan penyusunan laporan keuangan secara benar. Solusi yang ditawarkan yakni memberikan pelatihan dan pendampingan dalam pembuatan pembukuan sederhana untuk UMKM dan penyusunan laporan keuangan. Program kegiatan pengabdian telah dilaksanakan pada hari Kamis tanggal 19 November 2020. Pelaksanaan kegiatan pengabdian di Gerai Batik Kampung Tematik Durenan Indah, Kelurahan Mangunharjo Kecamatan Tembalang. Kegiatan tersebut dilaksanakan selama 1 (satu) hari dari pukul sepuluh sampai dengan pukul satu siang (selama tiga jam).
\end{abstract}

Kata Kunci : Kampung Tematik Durenan Indah, Batik Blekok, Batik Blibis

\begin{abstract}
One of the thematic villages in Tembalang sub-district is Mangunharjo Village with the name Durenan Indah Thematic Village which was built based on existing activities in the RW 06 area namely UKM "Batik. Blekok" and Batik, group activity "Blibis Mas" as a result of the assistance of UKM "Batik. Blekok. "In RW 06. The purpose of the establishment of Durenan Indah Thematic Village in RW 06 Manguharjo Village, Tembalang District, Semarang City is to increase knowledge or education about Nusantara culture, especially Semarang City Local Art and Culture, preserving national and local culture which characterizes the city of Semarang in general. and is a hallmark of the superior product of Mangunbarjo Village, community empowerment aims to reduce poverty and unemployment, beautify slum areas, uphold local wisdom in increasing potential and solving environmental problems, making the area a tourism area. The problems faced by SMEs Batik Blekok and UKM Batik Blibis include in the field of financial management, in this case is due to limited knowledge about the preparation and preparation of financial reports correctly. The solution offered is to provide training and assistance in making simple bookkeeping for MSMEs and preparing financial reports. The community service program was carried out on Thursday, November 19, 2020. The implementation of service activities at the Batik Outlet of Durenan Indah Thematic Village, Mangunharjo Village, Tembalang District. This activity is carried out for 1 (one) day from ten to one o'clock in the afternoon (for three hours).
\end{abstract}

Keywords: Thematic Village of Durenan Indah, Batik Blekok, Batik Blibis 


\section{PENDAHULUAN}

Kampung Tematik adalah program inovasi Pemerintah Kota Semarang dalam mengurangi permasalahan dalam memenuhi kebutuhan dasar yang utama antara lain meningkatkan kualitas wilayah rumah tinggal masyarakat dan sarana prasarana permukiman serta meningkatkan potensi perekonomian kreatif (Syarifa \& Wijaya, 2019). Kampung Tematik menjadi titik utama sasaran pihak Kelurahan untuk melakukan perbaikan antara lain perbaikan daerah lingkungan kumuh, melakukan penghijauan wilayah secara intensif, menjadikan masyarakat setempat aktif dan kreatif serta peningkatan potensi sosial ekonomi masyarakat wilayah tersebut (Martuti et al., 2017).

Keberadaan kampung tematik memberikan manfaat, hal ini berdampak pada masyarakat wilayah setempat, di antaranya lebih tertatanya sarana dan prasarana lingkungan, menambah pendapatan sehingga perekonomian meningkat artinya adanya perbaikan kesejahteraan masyarakat, mempengaruhi pemikiran positif warga sehingga mendorong timbulnya ide kreatif dan berkembang. Keberadaan kampung tematik pastinya akan menimbulkan daya tarik daerah yang lain untuk ikut serta meningkatkan potensi wilayahnya, sehingga masing-masing wilayah akan berlombalomba melakukan perbaikan semaksimal mungkin dengan khas-nya serta menumbuhkan sentra industri baru.

Salah satu kampung Tematik di wilayah kecamatan Tembalang adalah Kelurahan Mangunharjo dengan nama Kampung Tematik Durenan Indah (Hendro, 2019; Setiawan et al., 2020). Kampung tematik ini dibangun berdasarkan adanya kegiatan yang ada di wilayah RW 06 yaitu UKM "Batik Blekok" dan kegiatan kelompok Batik "Blibis Mas" hasil dari binaan UKM "Batik Blekok" di RW 06. Maksud dibentuknya Kampung Tematik Durenan Indah di RW 06 Kelurahan Manguharjo Kecamatan Tembalang Kota Semarang adalah meningkatkan pengetahuan atau pendidikan tentang budaya Nusantara khususnya Seni dan Budaya Lokal Kota Semarang, melestarikan budaya nasional dan lokal yang mana menjadikan ciri khas kota Semarang pada umumnya dan ciri khas unggulan produk Kelurahan Mangunharjo, pemberdayaan masyarakat bertujuan untuk menekan kemiskinan dan pengangguran, mempercantik daerah kumuh, menjunjung kearifan lokal dalam meningkatkan potensi serta pemecahan permasalahan lingkungan, menjadikan wilayah tersebut sebagai daerah pariwisata.

Gambar 1:

Pembangunan Fisik Kampung Tematik Durenan Indah
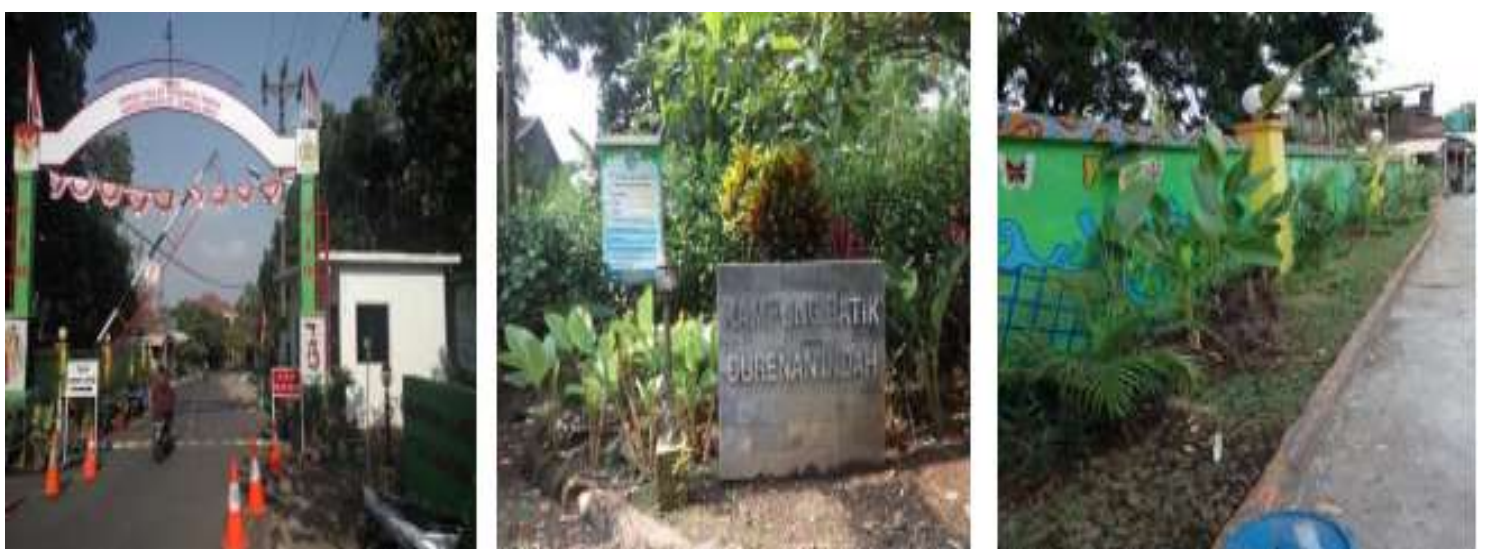
Selain batik, produk yang dihasilkan di Kampung Tematik Durenan Indah adalah Handycraft dan Kuliner. Berikut adalah beberapa hasil produk yang dihasilkan,

\section{Gambar 2:}

Hasil Produk Handycraft dan Kuliner
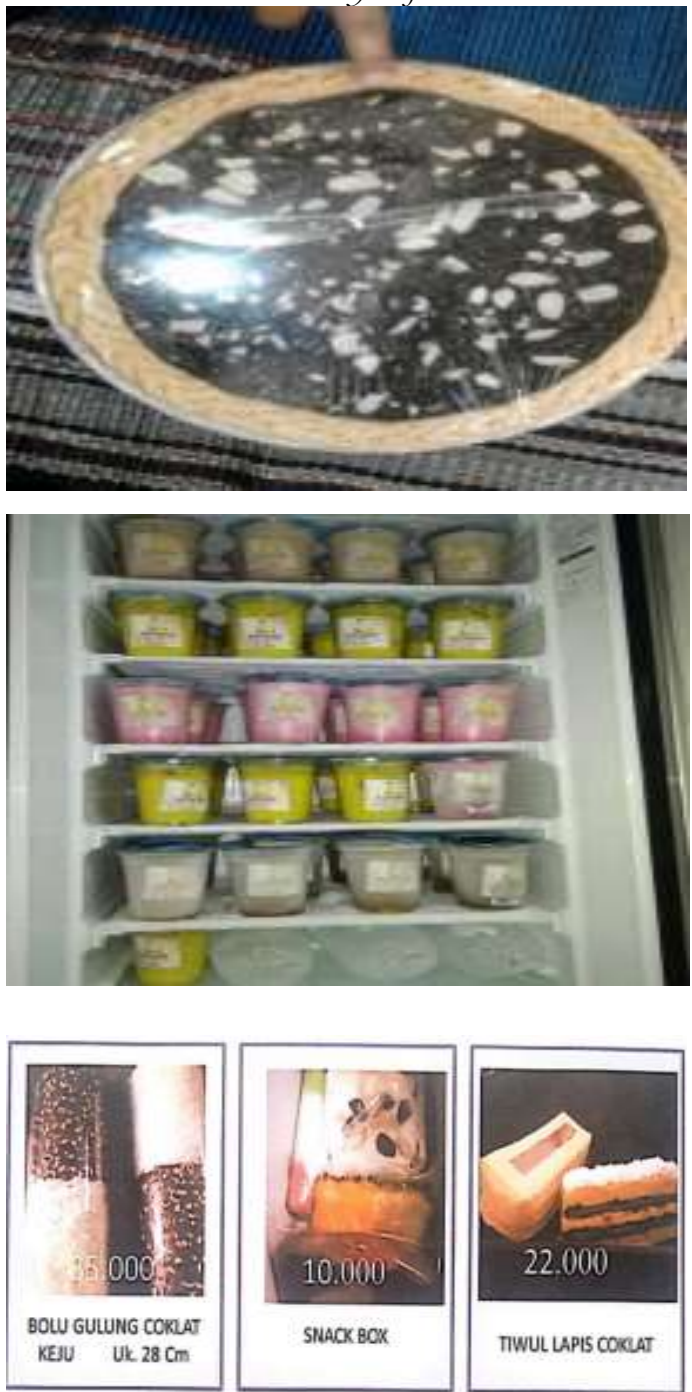

Kampung Tematik Durenan Indah mempunyai ruang pamer atau workshop yang terletak di beberapa RT yang tersebar di wilayah kelurahan Mangunharjo Kecamatan Tembalang Semarang. Berikut di bawah ini ruang pamer atau workshop untuk produk batik:
Gambar 3:

Galeri Batik RT 05 RW 06
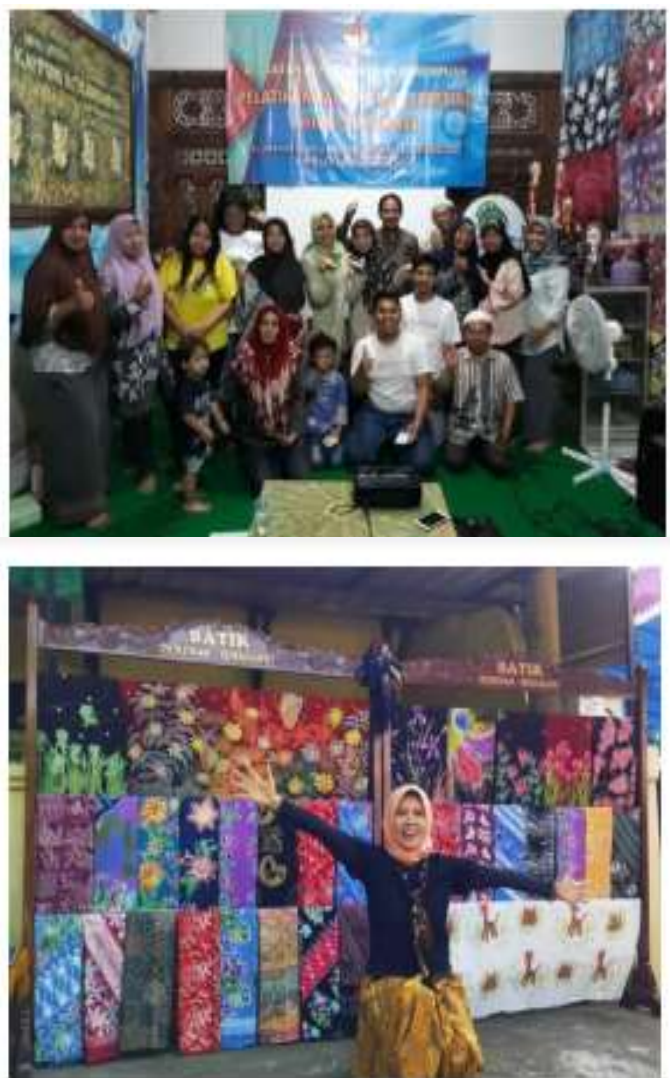

Di era digital sekarang ini sistem pemasaran produk kampung Tematik Durenan Indah Kelurahan Mangunharjo Kecamatan Tembalang menggunakan media Online antara lain Instagram, website dan Facebook serta yang terbaru yaitu membuat aplikasi di Play Store dengan nama "UMKM Mangunharjo".

Berdasarkan survei awal, UKM Batik Blekok dan UKM Blibis Mas Kelurahan Mangunharjo Kecamatan Tembalang, didapat informasi bahwa permasalahan yang utama adalah belum melakukan pencatatan keuangan dalam kegiatan usaha, hal ini dikarenakan minimnya pengetahuan tentang manajemen keuangan sehingga belum dapat menyusun laporan keuangan yang benar. 
Pelaku usaha pada umumnya masih mencampur aduk antara keuangan usaha dengan keuangan pribadi. Hal tersebut sesuai dengan penelitian, yang menjelaskan bahwa sebagai faktor utama yang menjadi kendala dalam pengembangan usaha (UKM) adalah pengelolaan keuangan usaha. Kesimpulan dari hasil penelitian, diketahui bahwa UKM yang belum memiliki laporan keuangan sebesar 77,5 persen sedangkan UKM yang memiliki laporan keuangan sebesar 22,5 persen (Hasyim, 2013).

Berdasarkan permasalahan tersebut, tim pengabdian akan melakukan kegiatan pelatihan dan pendampingan tentang penyusunan pembukuan sederhana terhadap pelaku usaha UMKM tersebut. Kegiatan pengabdian ini bertujuan untuk memberikan pelatihan penyusunan laporan keuangan kepada pelaku UKM. Mencari tambahan modal dari lembaga keuangan atau perbankan pada intinya harus menyertakan laporan keuangan. Tim pengabdian akan menyiapkan tentor yang memiliki kualifikasi di bidang akuntansi dan keuangan untuk memberikan pelatihan tentang penyusunan laporan keuangan sesuai yang dibutuhkan oleh mitra.

Kegiatan pengabdian bertujuan untuk meningkatkan serta menambah pengetahuan dan ketrampilan di bidang manajemen keuangan dan akuntansi sehingga pelaku UKM tidak mencampurkan antara keuangan usaha dengan keuangan pribadi. Pelaku usaha dapat menyusun laporan keuangan sehingga agar penerimaan, pengeluaran dan keuntungan yang diperoleh dapat diukur sehingga perkembangan usaha dapat terpantau.

Permasalahan yang dihadapi oleh pelaku usaha UKM Batik Blekok dan UKM Batik Blibis di antaranya di bidang manajemen keuangan, dalam hal ini adalah karena keterbatasan pengetahuan tentang pembuatan pembukuan sederhana dan penyusunan laporan keuangan yang benar.

Meninjau dari permasalahan yang dihadapi oleh pelaku usaha UKM Batik Blekok dan UKM Batik Blibis, maka tim pengabdian menawarkan solusi yaitu memberikan pelatihan dan pendampingan dalam pembuatan pembukuan sederhana untuk UMKM dan penyusunan laporan keuangan.

\section{METODE}

Tim pelaksana program pengabdian adalah Dosen Fakultas Ekonomi Universitas Semarang mentransfer ilmu melalui tahapan mendengar, memahami, mencoba, mempraktikkan dan disampaikan dengan bahasa sederhana.

Melalui proses kegiatan Tim PKM, diharapkan kedua mitra mempunyai kemampuan dalam pembuatan pembukuan sederhana serta kemampuan dalam menyusun laporan keuangan sehingga mitra dapat menganalisis perkembangan usahanya. Penyampaian materi kepada mitra melalui metode pelatihan dan pendampingan.

\section{HASIL DAN PEMBAHASAN}

Metode yang disampaikan ke mitra adalah metode pelatihan yang bertujuan untuk memberikan pengetahuan dan keterampilan tentang penyusunan laporan keuangan sederhana. Materi pelatihan tentang penyusunan pembukuan sederhana, terdiri dari pencatatan pemasukan dan pengeluaran kas, pencatatan piutang, pencatatan utang dan pencatatan stok barang.

Program kegiatan pengabdian diselenggarakan pada hari Kamis tanggal 19 November 2020. Pelaksanaan kegiatan pengabdian di Gerai Batik Kampung Tematik Durenan Indah, Kelurahan Mangunharjo Kecamatan Tembalang. Kegiatan tersebut dilaksanakan selama satu hari dari pukul sepuluh sampai dengan pukul satu (selama tiga jam).

Kegiatan Program Pengabdian kepada Masyarakat dihadiri oleh 18 (delapan belas) orang peserta, dengan perincian sebagai berikut : 
Tabel 1:

Daftar Nama Peserta Pengabdian

\begin{tabular}{|c|l|c|}
\hline No & \multicolumn{1}{|c|}{ Nama } & Alamat \\
\hline 1 & Ibu Istiari H & RT 06 \\
\hline 2 & Ibu Miranti M & RT 10 \\
\hline 3 & Ibu Puspita JKM & RT 04 \\
\hline 4 & Ibu Titis & RT 09 \\
\hline 5 & Ibu Wulan & RT 03 \\
\hline 6 & Ibu Yulia & RT 04 \\
\hline 7 & Ibu Sri Hartati & RT 03 \\
\hline 8 & Ibu Aisyah & Rt 05 \\
\hline 9 & Ibu Harwati & RT 07 \\
\hline 10 & Ibu Masniah & RT 05 \\
\hline 11 & Ibu Zumrotus S & RT 01 \\
\hline 12 & Ibu Asih & RT 02 \\
\hline 13 & Ibu Niken & RT 02 \\
\hline 14 & Ibu Sudarwati & RT 08 \\
\hline 15 & Ibu Puji Astuti & RT 04 \\
\hline 16 & Ibu wahyuningsih & RT 08 \\
\hline 17 & Ibu Ning Chrisna & RT 04 \\
\hline 18 & Ibu Rumiyati & RT 08 \\
\hline
\end{tabular}

Materi pelatihan yang akan disampaikan ke Mitra yakni UKM Batik di Kampung Tematik Durenan Indah Kelurahan Mangunharjo Kecamatan Tembalang sebagai berikut: Pertama, memisahkan rekening pribadi dan bisnis. Kedua, membuat format pembukuan, antara lain

a. Dokumen pendukung, yaitu dokumen sumber sebagai bukti sahnya transaksi yang dicatat dalam dokumen sumber, dalam hal ini berupa nota penjualan.

b. Pencatatan transaksi, merupakan kegiatan penting yang harus dilakukan oleh pelaku usaha agar terlihat cara memperoleh dan menggunakan dana.

c. Pencatatan Kas Masuk dan Kas Keluar, yaitu untuk memberi informasi tentang perolehan dan penggunaan dana.

d. Pencatatan Piutang. Bertujuan untuk mencatat mutasi piutang atau tagihan yang timbul dari transaksi penjualan kredit. e. Pencatatan Hutang. Bertujuan untuk mengetahui besarnya utang usaha yang diketahui dari kartu utang.

f. Pencatatan Stok Barang, merupakan kegiatan perhitungan persediaan stok barang di gudang sebelum dijual.

g. Pencatatan Laporan laba Rugi. Adalah laporan keuangan perusahaan berupa data pendapatan dan beban.

Dokumentasi pelaksanaan kegiatan pengabdian kepada masyarakat di kampung Tematik Durenan Indah Kelurahan Mangunharjo Kecamatan Tembalang sebagai berikut:

Gambar 1:

Pembukaan acara kegiatan PkM

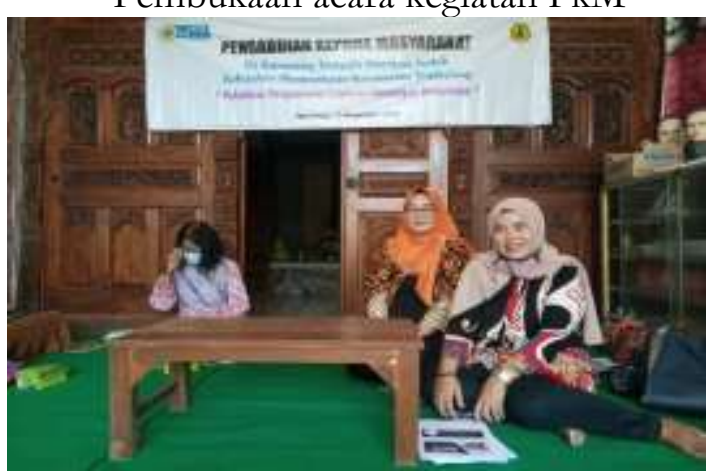

Gambar 2:

Penyampaian materi pencatatan transaksi, pencatatan piutang, Hutang dan Kartu Persediaan

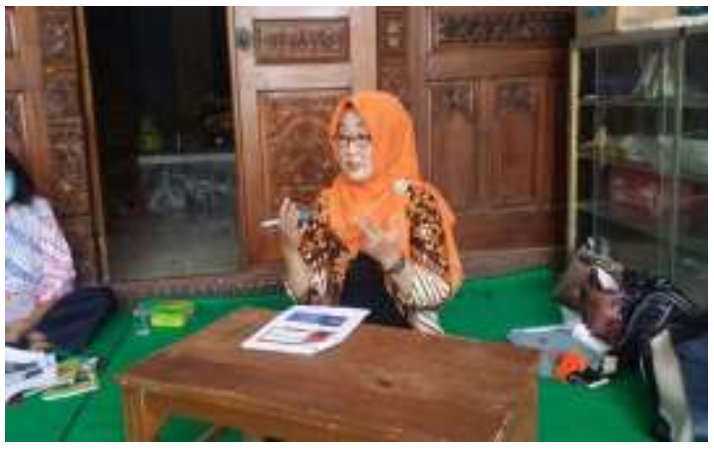


Gambar 3:

Penyampaian materi penyusunan laporan laba rugi

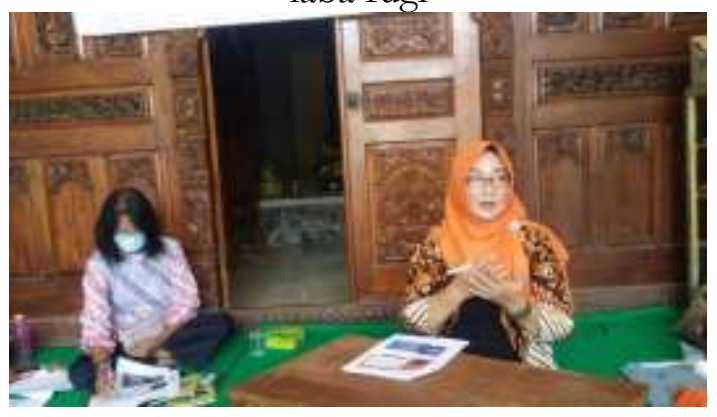

\section{KESIMPULAN}

Program kegiatan pengabdian telah dilaksanakan pada hari Kamis tanggal 19 November 2020. Pelaksanaan kegiatan pengabdian di Gerai Batik Kampung Tematik Durenan Indah, Kelurahan Mangunharjo Kecamatan Tembalang. Kegiatan tersebut dilaksanakan selama satu hari dari pukul sepuluh sampai dengan pukul satu (tiga jam).

Materi kegiatan program pengabdian kepada masyarakat yang disampaikan adalah cara penyusunan laporan keuangan sederhana, antara lain yang terdiri dari pencatatan transaksi, kas masuk dan kas keluar, pencatatan piutang, pencatatan hutang, pencatatan stok barang dan cara menyusun laporan laba rugi.

Respons warga mitra yang mengikuti kegiatan program pengabdian kepada masyarakat tentang cara menyusun laporan keuangan sederhana, sangat antusias dan sangat merespons baik. Bahkan warga mitra mengusulkan agar kegiatan program pengabdian kepada masyarakat ditindak lanjuti, agar warga mitra dapat lebih paham. Hal ini dimaksudkan karena sering mengikuti lomba administrasi kegiatan UMKM pemerintah kota Semarang.

\section{DAFTAR PUSTAKA}

Hasyim, D. (2013). Kualitas Manajemen Keuangan Usaha Mikro Kecil Menengah (UMKM) (Studi Kasus pada Distribution Store (Distro) di Kota Medan. JUPIIS, 5(2). https://doi.org/10.24114/JUPIIS.V5 I2.1119.G878

Hendro, E. P. (2019). Konsep Pengembangan Kampung Batik Durenan Indah Suatu Pendekatan Antropologi Terapan. Endogami: Jurnal Ilmiab Kajian Antropologi, 2(2), 176. https://doi.org/10.14710/endogami. 2.2.176-181

Martuti, N. K. T., Hidayah, I., \& Sumaryanto, T. (2017). Preferensi Masyarakat terhadap Program Kampung Tematik di Kota Semarang. Riptek, II(2), 11-22. https://riptek.semarangkota.go.id/ind ex.php/riptek/article/view/24

Setiawan, W., Sutjipto, E., \& Kusumo, W. K. (2020). PKM Durenan Indah di Kelurahan Mangunharjo, Kecamatan Tembalang, Kota Semarang. E-Dimas: Jurnal Pengabdian Kepada Masyarakat, 11(3), 307-315. https://doi.org/10.26877/edimas.v11i3.4384

Syarifa, N. H., \& Wijaya, A. (2019). Partisipasi Masyarakat dalam Kegiatan Pemberdayaan melalui Program Kampung Tematik (Studi Kasus di Kampung Batik Kelurahan Rejomulyo Kecamatan Semarang Timur Kota Semarang). SOLID ARITY, 8(1), 515531.

http://journal.unnes.ac.id/sju/index. $\mathrm{php} /$ solidarity 